\title{
Patient Related Factors Associated with Long-Term Urinary Continence After Burch Colposuspension and Pubovaginal Fascial Sling Surgeries
}

\author{
Holly E. Richter ${ }^{1}$, Linda Brubaker ${ }^{2}$, Anne M. Stoddard ${ }^{3}$, Yan $\mathrm{Xu}^{3}$, Halina M. Zyczynski ${ }^{4}$, \\ Peggy Norton ${ }^{5}$, Larry T. Sirls ${ }^{6}$, Stephen R. Kraus ${ }^{7}$, Toby C. Chai ${ }^{8}$, Philippe Zimmern ${ }^{9}$, E. \\ Ann Gormley ${ }^{10}$, John W. Kusek ${ }^{11}$, Michael E. Albo ${ }^{12}$, and the Urinary Incontinence \\ Treatment Network \\ 1 University of Alabama at Birmingham \\ ²oyola University Chicago \\ ${ }^{3}$ New England Research Institutes, San Antonio \\ ${ }^{4}$ University of Pittsburgh, Magee-Womens Hospital, San Antonio \\ ${ }^{5}$ University of Utah, San Antonio \\ ${ }^{6}$ William Beaumont Hospital, San Antonio \\ ${ }^{7}$ University of Texas, San Antonio \\ 8University of Maryland, Southwestern \\ 9University of Texas, Southwestern \\ ${ }^{10}$ Dartmouth-Hitchcock Medical Center, San Diego \\ 11 National Institute of Diabetes and Digestive and Kidney Diseases, San Diego \\ ${ }^{12}$ University of California, San Diego
}

\section{Abstract}

Purpose-To examine pre-and post-operative patient-related factors associated with continence status up to 7 years post-surgery for stress urinary incontinence (SUI).

\begin{abstract}
Materials and Methods-Women randomized to Burch colposuspension or fascial sling surgery and assessed for the primary outcome of urinary continence two years post-procedure were eligible to enroll in a prospective observational study. Survival analysis was used to investigate baseline and post-surgery factors on subsequent risk of SUI defined as self-report of SUI symptoms, incontinence episodes on a 3-day diary or surgical retreatment.
\end{abstract}

Results-Seventy four percent (482/655) of women who participated in the randomized trial were enrolled in the follow-up study. Urinary continence rates decreased over a period of two to

() 2012 American Urological Association. Published by Elsevier Inc. All rights reserved.

Corresponding Author: Holly E. Richter PhD, MD Department of Obstetrics and Gynecology University of Alabama at Birmingham $61919^{\text {th }}$ Street South 176 F, Suite 10382 Birmingham, AL 35249 Phone: 205-934-1704 Fax: 205-975-8893 hrichter@uabmc.edu.

Publisher's Disclaimer: This is a PDF file of an unedited manuscript that has been accepted for publication. As a service to our customers we are providing this early version of the manuscript. The manuscript will undergo copyediting, typesetting, and review of the resulting proof before it is published in its final citable form. Please note that during the production process errors may be discovered which could affect the content, and all legal disclaimers that apply to the journal pertain.

Presented at the annual meeting of the American Urologic Association, May 14-19, 2011, Washington DC. 
seven years post-operatively from $42 \%$ to $13 \%$ in the Burch group and from $52 \%$ to $27 \%$, in the sling group, respectively. Among the baseline factors included in the first multivariable model age $(\mathrm{p}=0.03)$ prior SUI surgery $(\mathrm{p}=0.02)$, menopausal status $(0.005)$, urge index $(0.006)$, assigned surgery $(\mathrm{p}=0.01)$ and recruiting site $(\mathrm{p}=0.02)$ were independently associated with increased risk of incontinence. In the final multivariable model including baseline and post-operative factors, Burch surgery ( $\mathrm{p}=0.01)$, baseline variables of prior UI surgery $(\mathrm{p}=0.04)$, menopausal status $(\mathrm{p}=0.03)$ and post-surgery urge index $(\mathrm{p}<0.001)$, were each significantly associated with greater risk of recurrent urinary incontinence.

Conclusion-Pre- and postoperative urgency incontinence symptoms, Burch urethropexy, prior SUI surgery and menopausal status were negatively associated with long-term continence rates. More effective treatment of urgency UI in patients who undergo SUI surgery may improve longterm overall continence status.

\section{Keywords}

Stress urinary incontinence; urgency urinary incontinence; surgical outcomes

\section{Introduction}

Surgeons have an incomplete understanding of long-term surgical outcomes and risk factors for failure in women who undergo stress urinary incontinence (SUI) surgery. High-quality information on long-term surgical success rates and risk factors for failure are needed to help counsel patients. Complicating these issues further is that variability in success rates are noted secondary to differences in sample attrition, follow-up length and continence definition, with higher failure rates higher in studies with combined objective and subjective outcome measures. ${ }^{1,2}$

We previously reported that pre-operative severity of urgency urinary incontinence (UUI) symptoms, increasing stage of pelvic organ prolapse and post-menopausal state without hormone therapy were significant predictors of surgical failure for stress urinary incontinence at 24 months among women enrolled in a clinical trial of the Burch urethropexy and autologous rectal fascial sling (the Stress Incontinence Surgical Treatment Efficacy Trial, SISTEr). ${ }^{3}$ An often over-looked consideration is that the success of SUI surgery may also be influenced by patient related factors that arise post-operatively, including weight gain, ${ }^{4}$ development or worsening of $\mathrm{UUI}^{3}$ and new co-morbid medical conditions. ${ }^{5}$

Patient-reported outcomes following SUI surgery are also significantly affected by the presence of UUI. $6,7,8$ Thus a woman undergoing SUI surgery may develop new or experience continuing UUI post-operatively and may be viewed as a surgical failure although the procedure she underwent was not primarily intended to treat UUI.

In this report, we examined a range of pre-and post-operative patient related factors to determine their association with post-operative continence status up to 7 years after randomization to a Burch colposuspension or autologous rectus fascial sling surgery in women enrolled in an observational study, the Extended-Stress Incontinence Surgery Treatment Efficacy Trial (E-SISTEr).

\section{Materials and Methods}

The design and major findings from the SISTEr trial have been published previously. ${ }^{9,} 10$ Briefly, women planning surgery for SUI were eligible for the study. Women were randomized in the operating room on the day of surgery to either a Burch colposuspension 
or an autologous rectus fascial sling procedure. The primary outcome, ascertained at 2 years post-randomization, was overall surgical success strictly defined as a negative pad test, no urinary incontinence from a 3-day bladder diary, a negative cough and valsalva stress test, no self-reported symptoms of urinary incontinence and no retreatment for urinary incontinence. Stress-specific surgical success was defined as no symptoms of stress urinary incontinence, a negative stress test and no retreatment for stress incontinence. All women enrolled in SISTEr were eligible for this planned prospective observational study, ESISTEr. The observational study was approved by the Institutional Review Board of all participating institutions. All study participants provided written informed consent.

\section{Enrollment in SISTEr occurred between February, 2002 and June, 2004}

The first E-SISTEr visit took place in August, 2004. Study participants were contacted by telephone and mail every 6 months beginning 30 months post-randomized surgery for data collection. Follow-up continued until the administratively defined end of the study in February, 2010, providing a minimum of five years of follow-up post-randomized surgery. The E-SISTEr primary outcome of continence, modified from that used in the SISTEr trial, was strictly defined as no symptoms of urinary incontinence reported on a 3-day voiding diary, no reported stress urinary incontinence symptoms on the Medical, Epidemiologic, and Social Aspects of Aging Project (MESA) questionnaire"11 (response of "rarely" or "never" for each stress-type symptom) and no surgical retreatment for SUI. Continence status was defined conservatively when outcome data were not available; when one or more of the individual components of the outcome was missing, but another measure was positive (incontinence), the woman was considered incontinent. When one or more measure was missing and all other measures indicated continence, the participant was treated as missing and the subject not considered continent. We also assessed lower urinary tract symptom distress and impact with the Urogenital Distress Inventory (UDI) and Incontinence Impact Questionnaire (IIQ). ${ }^{12}$

Study participants were contacted by telephone every 6 months and asked to identify any additional SUI treatment including sling revision, urethral bulking injections, use of vaginal cones, continence pessaries, urethral plugs or patches, SUI-related medications and/or behavioral treatments. They were also asked about complications related to their SUI surgery including treatment for persistent or de novo UUI, urinary retention and/or prolapse.

The following pre-operative baseline factors were assessed for their association with continence status: age, race, marital status, education, income; UI (urinary incontinence) risk factors: body mass index (BMI), number of vaginal deliveries, prior UI surgery, prolapse stage, menopausal/HRT (hormone replacement therapy) status; quality of life from the UDI and IIQ ; UI clinical characteristics: incontinence episodes per day, MESA stress and urge indices scores, and Q-tip test and index surgical procedure. Post-operative information obtained by self-report during follow-up were changes in BMI (based on self-reported weight), MESA urge index score, use of anti-cholinergic medications, subsequent pelvic surgeries, feeling of vaginal bulging or protrusion and new health conditions.

\section{Statistical Methods}

Survival analysis methods were used to explore the trends in continence status over time since study assigned surgery. The time of the incontinence event is the first visit postsurgery at which the woman demonstrates incontinence by our measure described above. If a woman became incontinent between visits, her time to incontinence was set as the next visit. Women who remained continent were censored at the last visit for which we have data. Selected clinically relevant variables were measured at each SISTEr or E-SISTEr visit and the change over time post surgery in these measures was assessed by repeated 
measures analysis of variance (ANOVA) controlling for pre-operative baseline levels. Kaplan Meier product limit analysis was used to estimate the continence rates over time; Cox proportional hazards models were used to investigate the effect of covariates (baseline and time-varying) on continence status. Analyses were controlled for treatment group and surgical retreatment. All analyses were carried out with SAS statistical software, version 9.2 (SAS Institute).

\section{Results}

Seventy four percent (482/655) of the SISTEr participants were enrolled in E-SISTEr $(\mathrm{N}=243$, sling group and $\mathrm{N}=239$, Burch group). Of the 482 women enrolled, 446 (93\%) were followed $\geq 3$ years, $423(88 \%) \geq 4$ years and $399(83 \%) \geq 5$ years post-surgery. Median duration of follow-up was 6 years. Five-year follow-up rates by treatment group were similar, 200/243 (82\%) in the sling group and 199/239 (83\%) in the Burch group. Compared to those who declined enrollment, participation in E-SISTER, were significantly older (mean age 53 yrs. vs. 49 yrs, $\mathrm{p}=0.0001$ ) at baseline pre-operatively, and were more highly educated (percent with a college education or more $29 \%$ vs. $14 \%, \mathrm{p}=0.005$ ). E-SISTEr participants also exhibited greater severity of prolapse (79\% stage 2 or greater vs. $64 \%$, $\mathrm{p}=0.0009$ ) and were more likely to experience surgical failure during the first 24 months of follow-up $(56 \%$ vs. $34 \%, \mathrm{p}<0.0001)$ than non-participants. ${ }^{*}$

The urinary continence rate declined substantially in the Burch group from $42 \%$ (95\% confidence interval [CI]: $36 \% \mathbf{- 4 8 \%}$ ) in year 2 post-surgery to $24 \%$ (95\% CI: $\mathbf{1 9 \%}$ $\mathbf{3 0 \%}$ ) in year 5 and $13 \%$ (95\% CI:7\% - 18\%) in year 7. In that interval, rates in the sling group also decreased markedly from 52\% (95\% CI: $\mathbf{4 6 \%}$ - 59\%) to $34 \%$ (95\% CI: $\mathbf{2 8 \%}$ $\mathbf{4 0 \%}$ ) in year 5 and $27 \%$ (95\% CI: $\mathbf{2 0 \%}-\mathbf{3 3 \%}$ ) in year 7. In both groups the average yearly decrease in continence rate was 6 percent from the end of SISTEr (year 2 postsurgery) to year five post-surgery. The cumulative percent of participants who had undergone surgical retreatment was significantly higher $(26 \%, \mathrm{n}=29)$ in the Burch group than the sling group $(2 \%, \mathrm{n}=5, \mathrm{p}<0.001)$. Among post-operative time-varying factors considered, the mean \pm standard deviation MESA urge index score increased significantly, from $14 \pm 17$ at 24 months post-surgery to $18 \pm 20$ at five years, $\mathrm{p}<0.0001$; the prevalence of new medical conditions also increased from $5 \%$ at 24 months to $10 \%$, at five years $\mathrm{p}=0.02$. In contrast, mean BMI, the frequency of use of anti-cholinergic medications for bladder symptoms and the rate of self-reported feeling of bulging or protrusion remained stable over the same time period. Nevertheless these factors were included in a time-varying statistical model as they may have changed in individual women over time.

After controlling for surgery group and recruiting site, preoperative baseline factors individually associated with recurrent incontinence included age $(\mathrm{p}=0.01), \mathrm{BMI}(\mathrm{p}=0.01)$, prior UI surgery $(\mathrm{p}=0.01)$, menopausal status $(\mathrm{p}=0.009)$, and MESA urge index $(\mathrm{p}=0.0001)$. Post-operative factors individually associated with recurrence of incontinence included change in BMI ( $\mathrm{p}=0.02)$, any use of anti-cholinergic drugs $(\mathrm{p}<0.0001)$, the MESA urge index, $(\mathrm{p}<0.0001)$ and a feeling of vaginal bulging or protrusion $(\mathrm{p}=0.009){ }^{*}$

The first multivariable model to look at variables independently associated with longer-term continence status included only pre-operative baseline variables. Increasing age, prior UI surgery, menopausal status and increasing MESA urge index score as well as assigned surgery and recruiting site (Table $\mathbf{1}$ ) were significantly associated with decreasing continence rates and all remained significant with the exception of BMI when other

\footnotetext{
* For tables of baseline characteristics of E-SISTEr participants and individual associations of potential predictor variables with continence rates please go to: J Urol website url
} 
variables were controlled. A second final multivariable model included both baseline and post-operative covariates. Burch surgery $(\mathrm{p}=0.005)$, prior UI surgery $(\mathrm{p}=0.04)$, menopausal status $(\mathrm{p}=0.03)$ and higher postoperative MESA urge index score $(\mathrm{p}<0.0001)$, remained significantly associated with greater risk of recurrent incontinence (Table $\mathbf{1}$ ).

\section{Discussion}

Extended follow-up of the SISTEr participants provides important insights into the longterm experience of women who have undergone surgery for stress urinary incontinence. We recently reported that continence rates declined steadily over 7 years after both the Burch and sling arms among women enrolled in E-SISTEr, and that continence rates were lower in the Burch cohort as compared to the sling group. ${ }^{13}$ The high rates of post-operative incontinence led us to examine pre- and post-operative factors associated with long-term continence rates. Baseline factors associated with waning continence were the Burch procedure itself, a history of previous UI surgery, being post-menopausal without the use of hormone replacement therapy and higher MESA urge index. Among post-operative factors assessed, only increasing urgency incontinence symptoms were associated with declining continence rates.

Consideration of pre-operative factors that may negatively impact surgery for SUI is necessary to establish realistic expectations for patients who may believe that surgery will completely eliminate their incontinence. Patient expectation should be tempered for the two procedures studied since each had low continence rates over extended follow-up with the composite objective and subjective outcome measures that were used to define continence rates. ${ }^{13}$ It is important to note that while the Burch and sling procedures were designed to correct SUI, we observed that both pre-operative and post-operative UUI negatively impacts overall continence rates over the long-term in women who undergo these procedures.

Multivariable analyses indicated that the post-operative MESA urge index score assessed longitudinally was a significant predictor of continence rates over time. Whether increasing symptoms of UUI over time reflect the pathophysiology associated with the incontinence procedure itself or a consequence of ageing (or both) cannot be addressed by our data as there is no parallel comparator group of women who did not undergo surgery.

Many of the women enrolled in E-SISTEr had stress predominant, mixed urinary incontinence (MUI). Currently, there is no consensus on the best treatment approach for women with MUI specifically as to whether it is advantageous to treat the urge incontinence or stress incontinence first. ${ }^{14}$ Our findings suggest that since UUI, whether present at baseline or post-operatively, was strongly associated with a decrease in long-term continence rates, treatment of pre-operative urgency urinary incontinence should be considered.

The increase in the frequency of UUI observed in our cohort and the associated increase in the post-operative MESA urge index may be a result of increasing age and BMI, as well as the development of medical comorbidities. ${ }^{5}$ Although increasing age and BMI were significantly associated with decreasing surgical continence rates on the individual association analysis they were not significant independent risk factors in multivariable analysis. Thus in this population, there may be something intrinsic to having the continence surgery which contributes to the development of increasing UUI symptoms over time. In this study, the use of anti-cholinergic medications was also only significantly associated with decreasing continence rates in the individual association analysis, but not in the multivariable analysis. As anti-cholinergic medications are expensive and have bothersome side-effects, it is not surprising that their use did not parallel increasing UUI symptoms over 
time. It would be interesting in the future to see if more aggressive, early behavioral approaches in treating urge incontinence could lessen incontinence rates post-operatively.

We observed that post-menopausal women who were not taking HRT at the time of surgery were more likely to experience incontinence over the extended follow-up period. This may suggest that estrogen treatment may improve outcomes in certain women who undergo SUI surgery. As we did not standardize the use of estrogen replacement at any time postoperatively, we cannot determine the local effects of topical or systemic estrogen on postoperative outcomes. It is also not clear whether women who were not taking estrogen pre-operatively started estrogen during the follow up period.

We also found that women with a history of previous SUI surgery had nearly 1.5 times the risk of increased incontinence compared with women whose randomized surgery was their first continence surgery. Our finding is consistent with prior observations in women undergoing the Burch ${ }^{15,16}$ and midurethral sling procedures. ${ }^{17}$ Whether this increased risk of incontinence after multiple SUI surgeries is a result of periurethral scarring, nerve damage during dissection or a more generalized severe neuromuscular compromise that over time leads to decreased effectiveness deserves further study.

We note several limitations to our study. We relied on participant self-report; study participants were mailed questionnaires or contacted by telephone and may have provided inaccurate information. However, this was likely minimized by the fact that these women had participated previously for two years in a randomized clinical trial with repeated collection of information including many of the measures of E-SISTEr. Women who enrolled in the observational cohort had more urinary incontinence at the time of study entry compared to those not enrolled which may have resulted in the higher reported rates of incontinence during follow-up.

This study has several strengths. We enrolled nearly three-fourths of the original SISTEr clinical trial participants into this extended prospective observational follow-up. The minimum follow-up time period was five years and median length of follow-up six years, providing an excellent opportunity to characterize long-term continence rates and associated risk factors. Few women were lost to follow-up, with outcomes determined at five years in nearly 80 percent of the study participants. Study participants were recruited from centers located throughout the U.S. which may enhance the generalizability of our findings. Finally, a variety of outcomes were assessed to better characterize the impact of urinary leakage from the participant's perspective.

\section{Conclusion}

Among women who were followed for a minimum of 5-years after Burch colposuspension or pubovaginal fascial sling, prior SUI surgery, being menopausal without HRT, having undergone a Burch procedure and increased post-operative urgency incontinence symptoms were significantly associated with long-term incontinence. Knowledge of risk factors for surgical failure can be used to better inform our patients of the likelihood of long-term continence or decreased continence rates to be experienced as a result of these surgeries. Our data suggest that overall continence status in these women may be improved by proactive pre- and post-operative assessment and effective treatment of urgency urinary incontinence.

\section{Supplementary Material}

Refer to Web version on PubMed Central for supplementary material. 


\section{Acknowledgments}

Supported by cooperative agreements from the National Institute of Diabetes and Digestive and Kidney Diseases: U01 DK58225, U01 DK58229, U01 DK58234, U01 DK58231, U01 DK60379, U01 DK60380, U01 DK60393, U01 DK60395, U01 DK60397, and U01 DK60401. Support also provided by the National Institute of Child Health and Human Development and Office of Research in Women's Health.

\section{Abbreviations}

$\begin{array}{ll}\text { ANOVA } & \text { Analysis of variance } \\ \text { BMI } & \text { Body mass index } \\ \text { CI } & \text { Confidence interval } \\ \text { ERT } & \text { Estrogen replacement therapy } \\ \text { E-SISTEr } & \text { Extended Stress Incontinence Surgery Treatment Efficacy Trial } \\ \text { HRT } & \text { Hormone replacement therapy } \\ \text { HS } & \text { High school } \\ \text { IIQ } & \text { Incontinence Impact Questionnaire } \\ \text { MESA } & \text { Medical, Epidemiological and Social Aspects of Aging } \\ \text { MUI } & \text { Mixed urinary incontinence } \\ \text { SISTEr } & \text { Stress Incontinence Surgery Treatment Efficacy Trial } \\ \text { SUI } & \text { Stress urinary incontinence } \\ \text { UDI } & \text { Urogenital Distress Inventory } \\ \text { UI } & \text { Urinary incontinence } \\ \text { UUI } & \text { Urgency urinary incontinence }\end{array}$

\section{References}

1. Rehman H, Bezerra CCB, Bruschini H, et al. Traditional suburethral sling operations for urinary incontinence in women. Cochrane Database of Systematic Reviews. 2011; (Issue 1) Art. No.: CD001754. DOI: 10.1002/14651858.CD001754.pub3. (need date of accession).

2. Lapitan MCM, Cody JD, Grant A. Open retropubic colposuspension for urinary incontinence in women. Cochrane Database of Systematic Reviews. 2009; (Issue 4) Art. No.: CD002912. DOI: 10.1002/14651858.CD002912.pub4. (need date of accession).

3. Richter HE, Diokno A, Kenton K, et al. Predictors of treatment failure 24 months after surgery for stress urinary incontinence. J Urol. 2008; 179:1024. [PubMed: 18206917]

4. Haverkorn RM, Williams BJ, Kubricht WS 3rd, et al. Is obesity a risk factor for failure and complications after surgery for incontinence and prolapse in women? J Urol. 2011; 185:987. [PubMed: 21247603]

5. Markland AD, Richter HE, Fwu CW, et al. Prevalence and trends of urinary incontinence in adults in the United States, 2001-2008. J Urol. 2011; 186:589. [PubMed: 21684555]

6. Mahajan ST, Elkadry EA, Shott S, et al. Patient selected goals: perspectives on surgical outcomes one year after surgery. Am J Obstet Gynecol. 2006; 194:722. [PubMed: 16522404]

7. Burgio KL, Brubaker L, Richter HE, et al. Patient satisfaction with stress incontinence surgery. Neurourol Urodyn. 2010; 29:1403. [PubMed: 20976815]

8. Brubaker L, Stoddard A, Richter H, et al. Mixed incontinence: comparing definitions in women having stress incontinence surgery. Neurourol Urodyn. 2009; 28:268. [PubMed: 19274758]

9. Tennstedt S. Design of the stress Incontinence Surgical Treatment Efficacy Trial (SISTEr). Urology. 2005; 66:1213. [PubMed: 16360445] 
10. Albo ME, Richter HE, Brubaker L, et al. Burch colposuspension versus fascial sling to reduce urinary stress incontinence. N Engl J Med. 2007; 356:2143. [PubMed: 17517855]

11. Herzog AR, Diokno AC, Brown MB, et al. Two-year incidence, remission, and change patterns of urinary incontinence in non-institutionalized older adults. J Gerontol. 1990; 45:M67. [PubMed: 2313045]

12. Shumaker SA, Wyman JF, Uebersax JS, et al. Health-related quality of life measures for women with urinary incontinence: the Incontinence Impact Questionnaire and the Urogenital Distress Inventory. Continence Program in Women (CPW) Research Group. Qual Life Res. 1994; 3:291. [PubMed: 7841963]

13. Brubaker L, Richter HE, Norton PA, et al. Five year continence rates, satisfaction and adverse events of Burch urethropexy and fascial sling surgery for urinary incontinence. J Urol. 2011 In Press.

14. Brubaker L, Moalli P, Richter HE, et al. Challenges in designing a pragmatic clinical trial: the mixed incontinence-medical or surgical approach (MIMOSA) trial experience. Clin Trials. 2009; 6:355. [PubMed: 19625327]

15. Alcalay M, Monga A, Stanton SL. Burch colposuspension: a10-20 year follow-up. Br J Obstet Gynaecol. 1995; 102:740. [PubMed: 7547767]

16. Langer R, Lipshitz Y, Halperin R, et al. Long-term (10-15 years) follow-up after Burch colposuspension for urinary stress incontinence. Int Urogynecol J. 2001; 12:323.

17. Richter HE, Litman HJ, Lukacz ES, et al. Demographic and clinical predictors of treatment failure one year after midurethral sling surgery. Obstet Gynecol. 2001; 117:913. [PubMed: 21422865] 


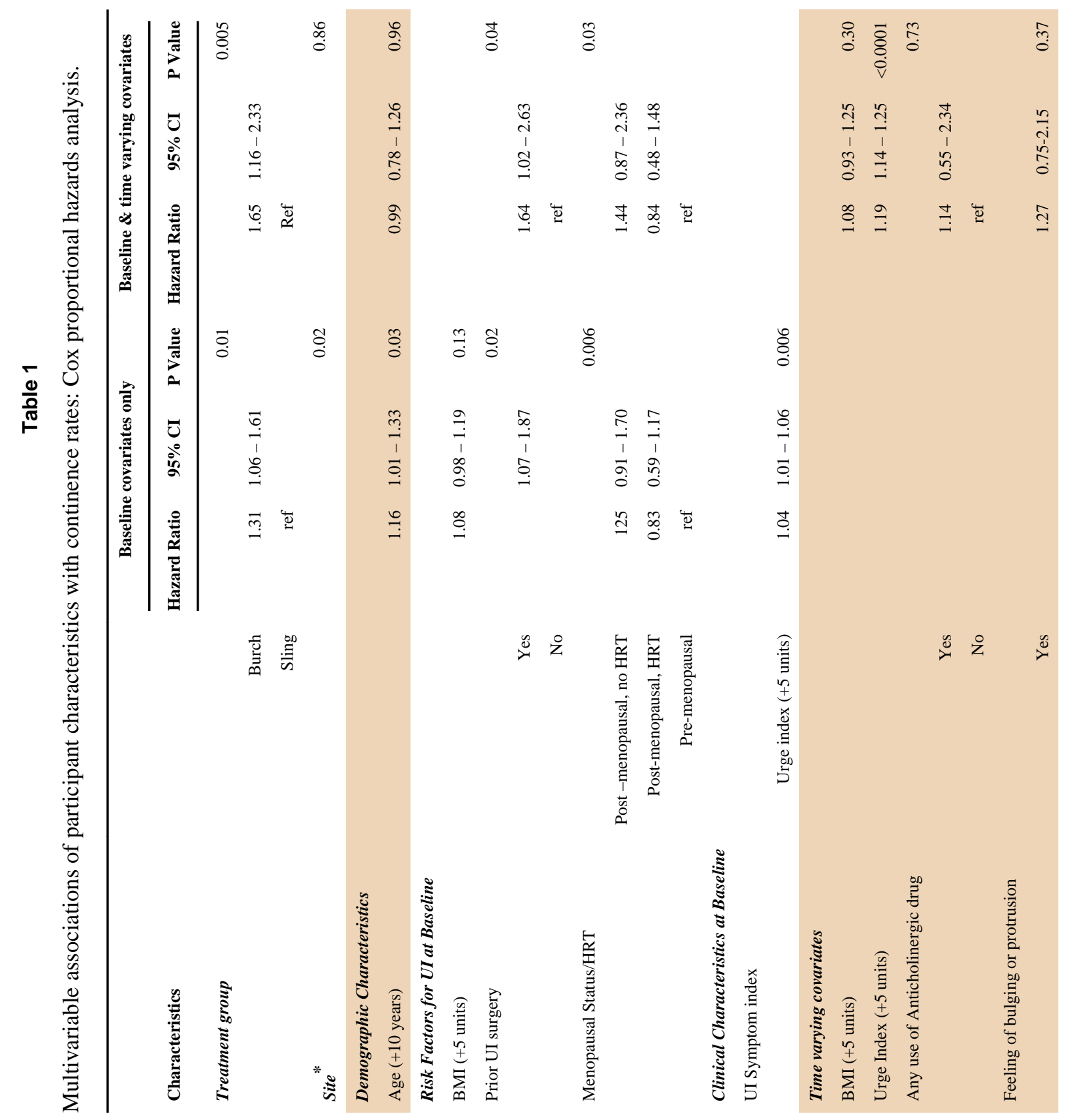




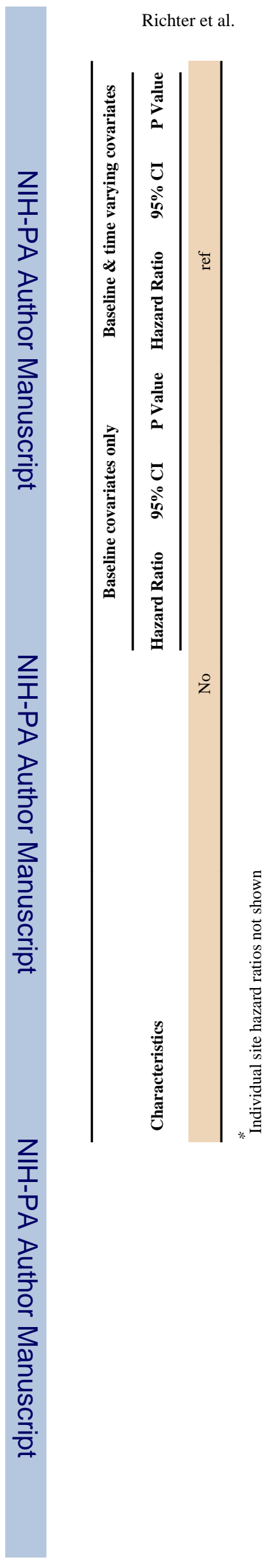

Page 10 